\title{
A educomunicação e o jornalismo como ferramenta de ensino na aprendizagem para alunos de ensino médio
}

\author{
Educommunication and journalism as a teaching tool in learning for high \\ school students
}

1 Juliana Soares Aragão ju.s.aragao@gmail.com

1 Maria da Conceição Vinciprova Fonseca

1 UniFOA - Centro Universitário de Volta Redonda.

\section{Resumo}

0 presente trabalho tem como objetivo construir, com a utilização da Educomunicação e do Jornalismo, uma estratégia lúdica de ensino/aprendizagem para alunos do Ensino Médio, especificamente ligada à saúde e ao meio ambiente, que colabore para o desenvolvimento da autonomia dos alunos. Este estudo envolve a transdisciplinaridade, isto é, disciplinas que colaboram entre si, sendo, portanto, um conceito integrador. A proposta vem ao encontro do ambiente contemporâneo, que faz uso de mídias e ferramentas virtuais para transformar o comum, o cotidiano, em tarefa que possa ser usada para educar, aprender e ensinar. Sendo assim, foi pensado o projeto desta pesquisa, que foi inicialmente submetido ao Comitê de Ética em Pesquisa com Seres Humanos, tendo sido aprovado com o número 16258819.0.0000.5237. Foi então aplicada uma oficina para alunos de uma escola pública de Barra Mansa-RJ, que deveriam participar da elaboração, apuração e produção do produto final deste trabalho: um vídeo-reportagem, feito usando o processo de vídeos gravados, via celulares, pelos próprios alunos. O resultado do trabalho, feito dentro e fora de sala de aula com a utilização de ferramentas midiáticas, evidencia que a busca pela notícia e a apuração da informação se tornam grandes aliados a pontos motivadores de conhecimento ligados à autonomia e criticidade do aluno, e constitui um instrumento de ensino a ser divulgado e experimentado por outros docentes.

\section{Palavras-chave:}

Educomunicação. Jornalismo. Educação.

\section{Abstract}

This work aims to build, with the use of Educommunication and Journalism, a playful teaching / learning strategy for high school students, specifically linked to health and the environment, which collaborates for the development of students' autonomy. This study involves transdisciplinarity, that is, disciplines that collaborate with each other, being, therefore, an integrating concept. The proposal meets the needs of the contemporary environment, which makes use of media and virtual tools in order to change the common, the daily, into a task that can be used to educate, learn and teach. Therefore, the project for this research was considered, and it was initially submitted to the Ethics Committee on Research with Human Beings, having been approved under the number 16258819.0.0000.5237. A workshop was then applied to students at a public school in Barra Mansa-RJ, who were supposed to participate in the elaboration, investigation and production of the final product of this work: a video report that was made using the process of videos recorded, via cell phones, by the students themselves. The result of the work, done inside and outside the classroom with the use of media tools, shows that the search for news and the verification of information can become great allies to motivating points of knowledge related to the autonomy and criticality of the student, and constitutes a teaching instrument to be disseminated and experienced by other teachers.

\section{Keywords:}

Educommunication. Journalism. Education.

\section{Como você deve citar?}

ARAGÃO, Juliana Soares; FONSECA, Maria da Conceição Vinciprova. A educomunicação e o jornalismo como ferramenta de ensino na aprendizagem para alunos de ensino médio. Cadernos UniFOA, Volta Redonda (RJ), v. 16, n. 46, p. 1-9, ago, 2021. 


\section{INTRODUÇÃO}

Não se poderia prever a evolução digital, que permite hoje a um grande número de pessoas dispor de computadores portáteis, os quais podem ser carregados facilmente em bolsos ou carteiras. Tal desenvolvimento chegou a todos os campos do conhecimento e da vida humana e, com certeza, modificou os paradigmas da educação. Hoje há dificuldade em conseguir que as pessoas, e entre elas os alunos, disponham um tempo maior para leitura e escrita, pois as tecnologias oferecem informação fácil, imediata, a um toque do dedo.

Sendo assim, cabe questionar se haveria uma maneira de ensinar e aprender que unisse tecnologia, ação, pesquisa e estímulo à criatividade, vindo assim a ser motivadora e levando os alunos a despertar seu interesse pela leitura e escrita a partir de assuntos relevantes para eles, contribuindo para sua autonomia em relação a seu conhecimento e à sua vida.

Tal reflexão levou a pensar este trabalho, no qual se busca utilizar a Educomunicação para enriquecimento do processo ensino-aprendizagem, com o desenvolvimento da autonomia para a criação e produção de materiais audiovisuais ou impressos, produzidos por alunos do Ensino Médio. Portanto, pretende-se apresentar formas de educar com a Educomunicação, fazendo uso de instrumentos midiáticos para tornar o ambiente de sala de aula mais leve e prazeroso. Propõe-se, neste trabalho, uma forma de se obter êxito e conseguir o máximo da qualidade no processo de ensino-aprendizagem utilizando ferramentas comuns do dia a dia, como o celular, para compor, apurar, informar e aprender dentro e fora de sala de aula.

A educação caminha junto com a evolução da tecnologia nesse processo, atualizando e renovando conhecimentos, mergulhada na reciclagem virtual que, de modo por vezes imperceptível, leva a sociedade contemporânea a adaptar-se, e mais, modificar-se para o uso de ferramentas antes não tidas como necessárias, e nem imaginadas, no cotidiano educacional. Convém salientar que, de acordo com o pensamento de Machado (2008), somente a educação garantirá que as tecnologias da informação e da comunicação promovam qualidade de vida ao maior número possível de cidadãos. Este trabalho se justifica uma vez que a Educação caminha juntamente com a comunicação, podendo-se afirmar que não existe educação sem comunicação. Rodrigues (2012) reflete sobre o fato de a aula ser um cenário onde coexistem múltiplas variáveis e a aprendizagem depende da ótima interação entre professores e alunos em um certo contexto.

Este estudo envolve a transdisciplinaridade, isto é, disciplinas que colaboram entre si, sendo, portanto, um conceito integrador. Com a aplicação da Educomunicação, pode-se aproveitar uma determinada disciplina para compreensão de outras. Ela trabalha a unidade do conhecimento e procura, de certa forma, estimular uma nova compreensão da realidade, ligando elementos que passam entre, além e por meio das disciplinas.

A proposta vem ao encontro do ambiente contemporâneo, que faz uso de mídias, ferramentas virtuais, aproveitando a possibilidade para transformar o comum, o cotidiano, em tarefa que possa ser usada para educar, aprender e ensinar. Silva (2006) já previa a importância da interconectividade que a Internet e as redes desenvolveram nesses últimos anos e que está a mudar, gradualmente, a forma de ensinar e aprender.

Acredita-se que a proposta deste trabalho possa significar maior participação para o universo escolar, com um grande envolvimento, tanto por parte do corpo discente como do corpo docente, ambos contribuindo para construção do conhecimento, utilizando pesquisas e produções midiáticas. 
Desse modo, o trabalho possui como objetivo geral otimizar, com a utilização da Educomunicação e do Jornalismo, o desenvolvimento da autonomia dos alunos do Ensino Médio com a construção de uma estratégia lúdica de ensino/aprendizagem especificamente ligada à saúde e ao meio ambiente.

Para tal, são objetivos específicos contribuir para a criação de um espaço para discussão de assuntos atuais, utilizando como ferramenta a Educomunicação; colaborar com o docente na utilização da Educomunicação para que um conteúdo midiático transforme-se em conteúdo educacional e de interesse para a disciplina; auxiliar o aluno na prática da linguagem e disposição para assumir seu lugar de fala (RIBEIRO, 2019); e apoiar o aluno a se construir como sujeito de seu discurso e responsável por sua comunicação.

Este estudo se apoia na perspectiva do crescimento da Educomunicação com a utilização de ferramentas virtuais. A hipótese é que a Educomunicacao deve contribuir no processo ensino-aprendizagem e motivar os alunos a buscar seu conhecimento, levando-os a produzir pesquisa, o que favorecerá sua autoestima e suas qualidades de pesquisador.

Por fim, o trabalho apresenta uma oficina para alunos de Ensino Médio, realizada no Colégio Estadual Baldomero Barbará, em Barra Mansa, com explanação e recursos visuais aplicados pela autora para conhecimento sobre conceitos de Jornalismo. Posteriormente, foi aplicada a proposta de elaboração de um vídeo-reportagem, em um processo de produção de vídeos gravados pelos alunos via celular, utilizando ferramentas da Educomunicação que abordem pautas relacionadas à Ciência da Saúde e/ou Meio Ambiente.

\section{DESENVOLVIMENTO}

Entende-se que não existe educação sem comunicação. 0 processo de ensino-aprendizagem apenas ocorre quando se efetiva a comunicação entre aluno e professor, um espaço de conversa. Uma das formas de trabalhar essa pluralidade de interesses é por meio da mídia-educação.

Soares (2000, p. 85) apresenta a Educomunicação como um conjunto de ações com vistas

(...) ao planejamento, implementação e avaliação de processos e produtos destinados a criar e fortalecer ecossistemas comunicativos em espaços educativos, melhorar o coeficiente comunicativo das ações educativas, desenvolver o espírito crítico dos usuários dos meios massivos, usar adequadamente os recursos da informação nas práticas educativas, e ampliar capacidade de expressão das pessoas. (SOARES, 200, p.83).

Para Freire (2006), não pode haver comunicação sem diálogo, e sem diálogo, não se executa verdadeira educação. A compreensão de que ensinar não é transferir conhecimento é extremamente necessária para o formando, para que ele compreenda a necessidade de criar possibilidades para a produção ou construção do saber, e não uma mera transferência de conteúdos e conhecimentos acumulados pelo sujeito que sabe e os transfere ao outro.

A Educomunicação é necessária justamente porque cabe à escola tentar fazer a análise crítica do que é tratado em classe trazido dos meios de comunicação. "Este nos parece ser seu maior desafio, já que os professores também sofrem essa ação” (GAIA, 2001, p. 41).

O entrosamento das Tecnologias da Informação e Comunicação, as TICs, junto ao cenário social e educacional, com relação a alunos e mestres, é diariamente crescente, e cada vez mais se exige da escola, e, por conseguinte, dos professores, a preparação dos alunos para uma sociedade competitiva e em constante mutação. Conforme Silva (2004, p. 3), "a utilização das TICs enquadra-se na visão atual 
da escola. Elas potenciam a organização e planificação das atividades, podendo também rentabilizar as aprendizagens".

A evolução da tecnologia está em crescimento veloz. As novas mídias, antes lançadas em intervalos consideráveis, muitas vezes já estão superadas por outras mais novas antes mesmo que se possa aprendê-las. Por sua vez, a sociedade está aprendendo por livre arbítrio a fazer as melhores escolhas, quanto às ferramentas que lhe são mais úteis.

Assim como a educação está aderindo à modernidade e participando da evolução da tecnologia, "(...) a escola deve integrar as tecnologias de informação e comunicação, porque elas já estão presentes e influentes em todas as esferas da vida social." (BELLONI, 2005)

Os meios de informar o aluno são diversos, e o uso da tecnologia facilita acesso à informação, as ferramentas que funcionam como pontes do mundo virtual para a sala de aula, segundo Moran, que afirma:

\begin{abstract}
são diferentes formas de representação da realidade, mais abstratas ou concretas, mais estáticas ou dinâmicas, mais lineares ou paralelas, mas todas elas, combinadas, integradas possibilitam uma melhor apreensão da realidade e o desenvolvimento das potencialidades do educando, dos diferentes tipos de inteligência, habilidade e atitudes (MORAN, 2007, p. 52).
\end{abstract}

Estudar pode se tornar uma ação maçante se não estiver adaptada ao interesse do aluno. É preciso incentivar os estudos, e com as Tecnologias de Informação e comunicação (TICs), pode-se abusar das ferramentas diferentes e sutilmente diferenciadas que cumpram esse papel. Moran considera importante humanizar as tecnologias: são meios, caminhos para facilitar o processo de aprendizagem (MORAN, 2007).

Esses recursos englobam a educação midiática como um utensílio para agregar ao ensino, e há de se encontrar uma maneira de chamar a atenção do aluno autodidata. Segundo Freire (2011), o educador democrático não pode se negar o dever de, na sua prática docente, reforçar a capacidade crítica do educando, sua curiosidade, sua insubmissão. Entende-se que isso signifique também permitir a prática de inovar ferramentas modernas para melhor compreensão no processo de ensino-aprendizagem, tanto para o aluno como para o professor.

Como não se pode negar o avanço da modernidade infiltrada em diversas atividades do dia a dia, surge assim a proposta de somar ao ensino a criação de uma ferramenta que possa auxiliar na humanização de assuntos complexos, no convívio direto e no ambiente informal de estudo. Aproximar os indivíduos da sociedade tecnológica utilizando o mundo virtual permite que o seu processo de relação com ele seja mais estreito e eficaz, uma vez que o aprendizado acontece em comunidade. As TICs pontecializam as interações, criando novos espaços de aprendizagens. (VIGOTSKY apud MACHADO, 1984)

O trabalho com abordagem no Jornalismo quer motivar os alunos a buscar informações de seu interesse, ler criticamente e melhorar a escrita por meio da prática. Eles deverão ir a campo, apurar notícias e produzir textos. Dessa forma, o trabalho feito com diversas ferramentas do ensino-aprendizagem pode criar uma certa informalidade na relação entre professor/a e alunos, tornando o processo mais leve e, porque não, prazeroso. " $O$ sujeito que se abre ao mundo e aos outros inaugura com seu gesto a relação dialógica que se confirma como inquietação e curiosidade, como inconclusão em permanente movimento na História" (FREIRE, 2007).

Para Prado e Satuf (2019), a experiência e uso de ferramentas jornalísticas, como apuração, levantamento, coleta, tratamento, análise de dados e de composição narrativa tem uma relevância grandiosa. "É imprescindível explorar as possibilidades comunicativas das linguagens que permeiam formatos áudio-verbo-visuais". (PRADO e SATUF, 2019, p.n.) 
O Jornalismo faz parte do cotidiano de todos, haja vista que a comunicação, o relato de fatos está por toda parte. Seja na televisão, no rádio, na banca de jornal ou na Internet, em algum momento do dia, todos se deparam com algum tipo de informação. Dessa forma, os conhecimentos, juntamente com as crenças de cada um, vão formando percepções e visões diferentes de acordo com sua vivência e o que lhes é passado pela mídia. "Na verdade, o discurso jornalístico constrói uma realidade que permite ao público produzir representações da sua relação com a realidade concreta” (CITELLI, 2012, p. 42).

Segundo Freire (2007), é extremamente necessário o reforço na afirmação de que o saber do professor, aquilo que vai ensinar, não é transferir conhecimento, não deve ser apenas apreendido por ele e pelos alunos, mas também ser constantemente vivido.

Em estudo sobre Vygotsky, Rego (1995) teoriza que o desenvolvimento cognitivo do aluno se dá por meio da interação social, ou seja, de sua interação com outros indivíduos e com o meio. A aprendizagem é uma experiência social, mediada pela interação entre a linguagem e a ação. "Aquilo que é a zona de desenvolvimento proximal hoje será o nível de desenvolvimento real amanhã - ou seja, aquilo que uma criança pode fazer com assistência hoje, ela será capaz de fazer sozinha amanhã" (VYGOTSKY apud REGO, 1995)

Ensinar, aprender e pesquisar são processos importantes na formação do educando, pois se aprende o conhecimento já existente e pode-se produzir conhecimento ainda não existente ou pouco enfatizado. Freire (2007) destaca a importância da ligação entre ensino e pesquisa na educação. 0 docente exige a busca, a indagação que se concretiza por meio da pesquisa. "Não há ensino sem pesquisa e pesquisa sem ensino" (FREIRE, 2007, p. 32)

Freire (2007) diferencia a educação dominadora e desumanizante, em que ocorre a pura transferência de conhecimento, de uma educação entendida como libertadora e humanizante, que representa o ato de conhecer, o processo do conhecer como desenvolvimento de consciência, com uma intencionalidade.Segundo Fonfoca (2009), Educação e Comunicação caminham para o reconhecimento dos mecanismos midiáticos como interdiscursivos. Para ele, as formas de aprendizagem transitam como formas de saberes implicados na formação de um cidadão que se atualiza, que busca incessantemente ligar o conhecimento a uma realidade, que se preocupa com a satisfação em aprender a aprender e, também, em aprender a conhecer.

É importante a participação dos alunos em sala de aula, a possibilidade da fala do discente "ter som", ser ouvida pelo professor. A troca de interesses docente/discentes pode proporcionar maior aproveitamento do tempo deles juntos. "O professor autoritário, que recusa escutar os alunos, se fecha a esta aventura criadora" (FREIRE, 2007, p. 92). 0 mesmo autor alerta que, quando isso ocorre, o docente recusa a afirmação do educando como sujeito do conhecimento.

\section{METODOLOGIA}

Este trabalho é um estudo do tipo exploratório, descritivo e de campo, desenvolvido a partir de questionário semiestruturado aplicado em uma escola estadual na cidade de Barra Mansa, no Sul Fluminense.

A pesquisa de campo foi feita em setembro de 2019, com alunos do Ensino Médio, sendo os critérios de inclusão serem alunos matriculados no colégio e terem assinados todos os documentos solicitados pelo Comitê de Ética em Pesquisa em Seres Humanos - CoEPS - UniFOA.

O trabalho foi iniciado após aprovação pelo CoEPS - UniFOA, CAAE, com o número 16258819.0.0000.5237. 
No primeiro momento, foram explicadas as ações do projeto às turmas do Ensino Médio e entregues termos de responsabilidade e concessão de imagem aos participantes, muitos menores de idade, que precisaram levar os documentos para os responsáveis. Devolvidos, os documentos foram posteriormente recolhidos e guardados.

No segundo momento, foi aplicada uma Oficina de Educomunicação em Saúde/Meio Ambiente para uma turma do segundo segmento do Ensino Médio, para a produção e elaboração de vídeos informativos, de curta duração (cerca de 3 a 5 minutos), com abordagens pré-definidas em conjunto (professor, alunos, pesquisadora).

Nesse mesmo momento, foram definidos os grupos, de três a cinco alunos, para que pudessem iniciar o processo de produção. Em sala de aula, foi montada uma reunião de pauta, para que os alunos pudessem sugerir temas e abordagens para serem trabalhadas por eles, de interesse comum da escola e/ou comunidade.

Com a ajuda da pesquisadora, jornalista de formação, os alunos tiveram uma breve explicação sobre entrevista e vídeos, assim como apuração, produção e montagem de roteiro.

Posteriormente, os grupos foram a campo, no decorrer de três semanas, para que pudessem apurar as informações, entrevistar, gravar, captar imagens e editar o material adquirido para conclusão do processo. Ao final, os vídeos foram apresentados em sala de aula, para que todos pudessem assistir à sua produção. Essa atividade permitiu que o aluno, antes apenas espectador, pudesse trocar de lugar e ser seu próprio informante de notícias de seu interesse e dos amigos.

Por fim, a proposta deste projeto foi concluída com um vídeo autoexplicativo da oficina, a Oficina Digital [SIC], de forma que se possa imediatamente entender como ela funciona e reproduzi-la. Esse vídeo-reportagem é o produto deste trabalho, a ser detalhado adiante.

A criação de uma oficina digital de Educomunicação abordando uma ferramenta virtual de audiovisual, com gravação e edição, vai ao encontro da proposta do projeto: tornar estudantes em pesquisadores questionadores e agentes da construção do próprio conhecimento. Com um leque imensurável de possíveis pautas e interesses, o aluno pode, com orientações e direções dos professores, escolher 0 melhor assunto para aquele determinado momento, seja do participante e/ou escola, dentro do cenário regional, estadual, nacional ou mundial.

Figura 1: 0 logo do produto.
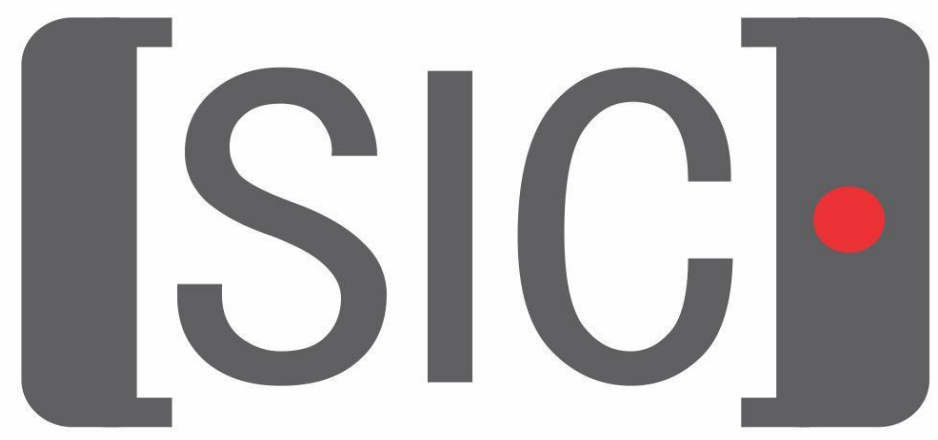

Fonte: autoria própria (2020). 


\section{DISCUSSÃO DE RESULTADOS}

A pesquisa e oficina proposta foram aplicadas no decorrer do último semestre de 2019. Foi criado um guia interno, com a função de organizar e dar direção aos planejamentos e explicar como deveriam ser aplicadas as ações.

As respostas aos questionários propostos evidenciaram que todos os participantes têm internet em casa, assim como telefones celulares. Foram entregues cerca de 100 questionários, todos com TCLE e Termo de Direito de Imagem, porém apenas 31 alunos responderam à pesquisa, dos quais somente um não tem câmera no celular. É importante frisar que esses 31 alunos fazem parte da turma onde foi realizada a oficina.

Ao serem questionados se já haviam realizado algum trabalho com vídeo-reportagem, a maioria respondeu que não, porém uma parte significativa se interessou, e 19 alunos afirmaram que gostariam de participar. Outros quatro responderam negativamente e os restantes (8), não responderam.

Já, quando questionados se fizeram algum vídeo com edição e música no celular, a divisão ficou com pouca diferença. A maioria se mostrou interessada em produzir uma peça audiovisual.

Quando questionados sobre assuntos que mais os interessam no celular, os alunos se dividiram em alguns temas.

Para a conclusão da pesquisa, foram levantados questionamentos sobre estudos com o uso do celular, e a turma foi unânime em responder que confia no processo de ensino-aprendizagem fazendo uso da ferramenta digital. Quanto ao possível uso do celular pelo professor para auxiliar no estudo, os participantes foram mais taxativos ao informar que fazem uso do aparelho para diversas finalidades, além de estudo também.

Cada grupo fez um vídeo-reportagem de três minutos, e esse material foi entregue no dia 26 de novembro de 2019, concluindo a oficina aplicada, que foi o produto deste trabalho. Essa oficina gerou um vídeo para ilustrar todas as etapas de produção, e o resultado deste trabalho está em um canal do YouTube criado e aberto para visualizações futuras de interessados no tema, chamado Oficina SIC. Para acessá-lo, basta digitar Oficina SIC no campo de busca da própria plataforma.

\section{CONSIDERAÇÕES FINAIS}

Neste estudo, verificou-se que os alunos e a escola podem ser, ao mesmo tempo, produtores e receptores de mensagens veiculadas nas mídias, tratando de assuntos de interesse à comunidade escolar e em geral. Os alunos se tornam protagonistas na emissão e difusão de conteúdo, e não somente na recepção. 0 alcance das mídias escolares pode não ser o mesmo dos produtos de grandes empresas, mas pode ser um processo transformador na aprendizagem e na relação entre alunos e professores.

O encontro da Comunicação Social com a Educação proporciona o acesso à cultura e à informação de maneira crítica e autômona. Dessa forma, a produção de mídias na escola é um trabalho rico, tanto para os alunos quanto para os educadores. Este trabalho comprovou sua eficácia no que se propõe: a contribuição para, com utilização da Educomunicação, contribuir para o desenvolvimento da autonomia dos alunos, dando um local mais amplo e real à educação e ao ensino. 
Pode-se compreender o alcance do trabalho pelo engajamento dos alunos e satisfação pelo produto final produzido por eles. Em diversos aspectos, o interesse para a colaboração ao criar um espaço para discussão de assuntos atuais envolveu os alunos dentro e fora de sala aula.

Tanto para os discentes quanto para o docente, foi verificado que o trabalho também conseguiu colaborar para a metodologia diversificada do professor, oferecendo o uso de um conteúdo midiático como conteúdo educacional que gerasse interesse para a disciplina.

O auxílio e apoio na construção do sujeito proporcionou ao aluno a anuência de tomar o seu discurso próprio, assumindo responsabilidade por sua comunicação e de forma que eles assumissem seu lugar de fala, leitura e escrita.

A ideia de deixá-los, como alunos, produzir o próprio conteúdo, na arte de pesquisar e informar, traz para dentro de sala de aula o poder de fala de cada indivíduo. Trata-se de uma forma de acolher e recepcionar a visão do aluno, deixando que eles formem e mostrem sua a visão crítica de um determinado assunto. Essa junção da Comunicação Social com a Educação produz neles a construção de conhecimento, com seu trabalho de promover a busca de determinada pauta, levando o aluno de uma posição de coadjuvante para protagonista de seu aprendizado.

Entretanto, obviamente, também é importante que sua produção faça parte de um projeto pedagógico bem planejado e estruturado. Não basta o veículo de comunicação ser bonito e bom aos olhos do educador, se o resultado final não for satisfatório. Ele deve funcionar como um instrumento do processo de ensino-aprendizagem, e não o aprendizado em si. Faz parte do processo, sendo inquestionável seu valor motivacional.

Além disso, o trabalho com uma ferramenta midiática explora a necessidade de exteriorização, de expressão dos alunos, o que muitas vezes não tem notoriedade no espaço público. Por meio da Educomunicação, é possível perceber o que os alunos pensam sobre diversos temas, quais assuntos Ihes despertam interesse, e assim, pensar em novas práticas pedagógicas e atividades para diversificar e enriquecer a proposta escolar.

\section{REFERÊNCIAS}

BELLONI, Maria Luiza. 0 que é mídia-educação. Coleção, Polêmicas do nosso tempo. 2. ed. São Paulo: Campinas: Autores Associados, 2001.

CITELLI, Adilson (org.). Educomunicação: Imagens do professor na mídia, 1 ed. São Paulo: Editora Paulinas, 2012.

FREIRE, Paulo. Pedagogia da autonomia: saberes necessários à prática educativa. 37. ed. São Paulo: Paz e Terra, 2007.

FONFOCA, Eduardo. Revisitar conceitos para obter novas possibilidades na Educomunicação. Blumenau, SC: Intercom, 2009.

GAIA, Rossana. Educomunicação e mídias. Maceió, AL: Edufal, 2001. 
MACHADO, A. C. T.; Novas formas de produção de conhecimento: utilização de ferramentas da web 2.0 como recurso pedagógico. Revista Udesc Virtu@l, v. 1, n. 2, 2008. Disponível em: http://revistas.udesc. br/index.php/udescvirtual/article/view/1655. Acesso em: 03 jun. 2019.

MACHADO, Elias. Dos estudos sobre o jornalismo às teorias do jornalismo (Três pressupostos para a consolidação do jornalismo como campo de conhecimento). E-Compós, v. 1, n. 11, 2004.

MACHADO, Jones; VIDOTO, S.; GARCEZ, C.; GONÇALVES, K.; ROSA, R. A Educomunicação como processo formativo: uma abordagem sobre violência no âmbito escolar. Anagrama, v. 3, n. 4, p. 1-13, 18 mar. 2010.

MORAN, Jose Manuel, A educação que desejamos: novos desafios e como chegar lá. Campinas, SP: Papirus Editora, 2007.

PRADO e SATUF (org.) Comunicação em Ambiente Digital, Comunicação, Filosofia e Humanidades, Unidade de Investigação, Universidade da Beira Interior. Covilhã, Portugal, 2019.

REGO, Teresa Cristina. Vygotsy: uma perspectiva histórico-cultural da educação. 14. ed. Petrópolis, RJ: Editora Vozes, 1995.

RIBEIRO, Djamila. Lugar de fala: feminismos plurais. São Paulo: Pólen, 2019.

RODRIGUES, David (org.). Educação Inclusiva: dos conceitos às práticas de formação. 2. ed. São Paulo: Editora Horizontes Pedagógicos, 2012.

SILVA, Adelina M. P. Processos de ensino-aprendizagem na Era Digital. Lisboa, Portugal: BOCC - Biblioteca On Line de Ciências da Comunicação, 2006.

SILVA, Álvaro A. T.; Ensinar e Aprender com as Tecnologias - Um estudo sobre as atitudes, formação, condições de equipamento e utilizacão nas escolas do 10 Ciclo do Ensino Básico do Concelho de Cabeceiras de Basto - Dissertação de Mestrado. Braga: Universidade do Minho, 2004.

SOARES, Ismar de Oliveira. Alfabetizacão e educomunicacão: o papel dos meios de comunicação e informação na educação de jovens e adultos ao longo da vida. São Paulo: USP, 2000. 